Volume 8, Issue 1, 87 - 97.

ISSN: 2165-8714

http://www.eu-jer.com/

\title{
The Sense of Classroom Belonging Among Pre-Service Teachers: Testing a Theoretical Model
}

\author{
Sıdıka Gizir * \\ Mersin University, TURKEY
}

Received: September 28, 2018 - Revised: November 5, $2018 \cdot$ Accepted: December 10, 2018

\begin{abstract}
The purpose of the present study is to test a hypothetical model in order to examine the association between students' sense of classroom belonging along with four other university class-level variables including faculty-student relationships, connected classroom climate referring peer relationships, loneliness and classroom identity. It is intended to draw attention of teacher educators to the importance of creating sense of community at classroom level through this study in order to improve the quality of teacher education. With this aim, pre-service teachers attending the faculty of education were selected as sample of the study $(\mathrm{N}=1425)$. Each measures used in this study was adapted for college-level students through confirmatory factor analysis in order to test specific predictions concerning each measure's structure and the results revealed that all measures have adequate psychometric properties. The model examined with structural equation modeling was an excellent fit with the data, and the results indicated that the fitted model explained $50 \%$ of the variance in classroom identity; $47 \%$ of the variance in sense of classroom belonging; $14 \%$ of the variance in classroom climate; and $9 \%$ of the variance in loneliness. Results and implications are discussed.
\end{abstract}

Keywords: Classroom belonging, classroom climate, classroom identity, faculty-student relationship, loneliness.

To cite this article: Gizir, S. (2019). The sense of classroom belonging among pre-service teachers: Testing a theoretical model. European Journal of Educational Research, 8(1), 87-97. doi: 10.12973/eu-jer.8.1.87

\section{Introduction}

The most recent studies focused on higher education indicated that one of the main causes of students' dropout from higher education or students' minimal academic and social integration is low level of students' sense of school belonging (Cox, Duncheon \& McDavid, 2010; Hoffman, 2014; Tuhanioglu, 2016; Uslu \& Gizir, 2017; Uslu-Gulsen, 2017). This situation has led universities to foster social integration or a sense of community among students. However the conditions or the factors positively related with university students' perceptions of belonging or sense of community has been unexplored in detail, although research has pointed out that students' sense of school belonging is one of the essential factors associated with positive aspects of students' school-related experiences. Accordingly a number of researchers have emphasized on the need for more research focused on university students' sense of belonging to further understand the role this plays in academic contexts (Booker, 2008; Freeman, Anderman \& Jensen, 2007; Pittman \& Richmand, 2008).

Evidence exists from younger samples that sense of belonging is achieved through reciprocally supportive social relationships among students and also between teachers and students, thus the focus is on durable, supportive and constructive interpersonal relationships (Allen at al., 2018; Finn, 1989; Lam, Chen, Zhang \& Liang, 2015; Uslu \& Gizir, 2017). Research has also indicated that unsatisfactory interpersonal relationships among students in the university are associated with low academic motivation; low achievement; academic disengagement; lack of belonging; loneliness; and poor self-esteem (Booker, 2008; Tuhanioglu, 2016). Similarly, it is stated that exclusion and social isolation or lack of belonging to other people in an educational context are associated with some undesirable experiences, for instance loneliness, anxiety, depression, lack of social adjustment (Allen at al., 2018; Newman, Lohman \& Newman, 2007; Tuhanioglu, 2016; Stoeckli, 2010). Lee and Robbins (2000) stated that a lack of belonging included feeling unrelated to others, having unsatisfactory friendships and not feeling as a member of a group, which are often described as a reflection of an enduring and general displeasure with social relationships. Thus Lee and Robbins proposed that these symptoms of lack of belonging can be placed under the category of loneliness. With the recognition of the negative outcomes of loneliness, defined as a basic sense of unconnectedness with other people in an educational context, researchers have focused on a student's need to belong in an educational context (Juvonen, 2007).

\footnotetext{
* Correspondence:

Sıdıka Gizir, Mersin University, Department of Educational Sciences, Turkey.

$\bowtie$ sgizir@mersin.edu.tr
} 
Furthermore, students' sense of classroom belonging is an important antecedent for students in order to identify themselves with their classmates (Finn, 1989; Voelkl, 1997). Individuals recognize how group norms, values, and other group characteristics can be influential on them when they see themselves as a part of the group (Bollen \& Hoyle, 1990). Accordingly, Osterman (2000) pointed out that a community exists when members feel themselves belong to the others in a social group. At university level, class can be viewed as the potential to become a community because all participants of the class are also members of the larger college community (Hirschy \& Wilson, 2002). The same participants study through numerous weeks or months in university classes, so they can be seen as social groups having beliefs, values, and norms that shaping members' attitudes and behaviors (Fassinger, 1997; Hirschy \& Wilson, 2002).

Briefly, students' experience of belonging is based on the presupposition that every beneficial social relationships between students and the others in an educational context, is contributive. At university level, faculty members and peers are seen as key social domains or groups where students develop close relationship, and then create sense of belonging, and also social identity within it. A supportive relationships between a student and the others led him/her to fell valued, confident, accepted, respected, and also experience lower levels of loneliness (Johnson, 2009; Hoffman, 2014; Ryan, 2001).

\section{Faculty- Student Relations}

In higher educational institutions, labor is divided, which means that different activities are carried out in the different parts connecting to each other in a coherent way, like in other organizations. Among these parts, Tinto (1997) emphasizes on university classrooms as unique context where faculty members and students meet and formal education is experienced. The main contribution to students' college experiences is made mainly via the classroom through course selection, course delivery method, and curriculum design by faculty as one of the most essential resources provided to students (Cotton \& Wilson, 2006). In education literature, it is also accepted that there is a relationship between student and teacher extent beyond formal interaction and the work of teacher can't be understood solely as the provision of knowledge; they must also be seen as people with whom the students will establish a social and affective relationship. Researchers suggest that teacher has a preponderant role in student's lives once they enter the educational environment, and that the relationship established between them can have a great influence on the way student adapt to it, both socially and academically (Duru, 2008; Lamport, 1993). It seems that faculty-student interactions occur in various forms, namely both formal and informal, as well as social and academic, and affect numerous student outcomes both negatively and positively in terms of student academic performance; satisfaction with college; intellectual and individual development; enjoyment of a class; sense of belonging; and career and educational aspirations (Allen at al., 2018; Cotton \& Wilson, 2006; Freeman, 2005; Halawah, 2006; Hoffman, 2014; Lamport, 1993; Meyers, 2009; Pascarella \& Terenzini, 1980; Pittman \& Richmond, 2008).

Moreover, a contact with faculty members is considered as 'a caring encounter' in the literature (Chickering, 1969; Tinto, 1997). Freeman, Anderman and Jensen (2007) pointed out that at every level of schooling, students' need to belong is satisfied when they perceive a school environment as caring. They also stated that a supportive interaction with a nonparental adult is beneficial for students to fulfill their belonging needs in a school environment. As a result of their study, Freeman and Anderman (2005, as cited in Freeman, 2005) stated that freshmen college students define caring professors as "those who are personable, who offer students assistance in the learning of course material, communicate a "caring" attitude, know students, appear available, and provide informative feedback" (p. 8). Meyers (2009) emphasized that expressing care toward students; behaving responsively, showing respect, interesting in their needs and remaining warm, not only improve individual relationships, but also affect the whole classroom climate and reduce conflicts within the classroom. Several studies noted that caring is an important dimension of effective college teaching, and makes a difference in students' educational experiences (Meyers, 2009). Specifically, Booker (2008) remarked that a students' sense of belonging is fostered through faculty-student relations characterized by warmth, cooperation, respect, and support. Research on college student populations revealed that perceived faculty caring has been associated with the fulfillment of students' belonging needs at the university level, greater involvement in campus organizations, higher academic performance and higher academic motivation (Chickering \& Reisser, 1993; Freeman, 2005; Freeman \& Anderman, 2005, as cited in Freeman, 2005; Tinto, 1997).

\section{Connected Classroom Climate and Loneliness}

In addition to interactions with faculty members, the importance of relationship among students with respect to their social integration into university has been emphasized in the related literature (Anderman 2003; Dwyer et al., 2004; Freeman, Anderman \& Jensen, 2007). Research has shown that peer acceptance, friendship with classmates and supportive relations among students referring to connected classroom climate promote sense of belonging, school engagement, persistence, self-esteem and academic motivation, while lack of friends or lack of connection with classmates is related with loneliness, estrangement, and student drop out or attrition (Booker, 2008; Duru, 2008; Freeman, 2005; Freeman, Anderman \& Jensen, 2007; Juvonen, 2009). Freeman (2005) stated that students' perceived support from other students as well as their teachers leads students to behave in socially accepted ways in their school context, and also to experience sense of belonging. It was also acknowledged that students' perceptions on teachers' 
emphasis on cooperation and supportiveness among students in order to build social connections in class confirmed positive relationships with students' feeling of relatedness (Cox, Duncheon \& McDavid, 2009).

Although the student-teacher interactions in an educational context has been main research topics in the related literature (Dwyer et al., 2004), Sidelinger and Booth-Butterfield (2010) emphasized on classroom connectedness, including positive connectedness and friendship among students in the classroom. Juvonen (2009) pointed out that friendships with classmates or supportive relationships foster sense of belonging and student involvement in schoolrelated activities, while nonexistence of such a connection with classmates are associated with undesirable experiences, such as loneliness and alienation. As in the studies conducted with younger populations, Freeman, Anderman and Jensen (2007, p.208) emphasized that students develop sense of belonging when they perceive that they are accepted, respected and valued by other students in the school. Furthermore, Fassinger $(1995 ; 1997)$ found that the perception of peer friendliness is more important predictive factor in students' in-class involvement more than the perception of the relationship between the students and the faculty.

Moreover, literature review revealed that connectedness is an important factor to foster a constructive and supportive classroom climate and sense of belonging for college students, even in larger classrooms (Sidelinger \& BoothButterfield, 2010). Students' perceptions of a supportive and cooperative classroom communication atmosphere referring a strong intra-group bond is named as connected classroom climate (Dwyer et al., 2004, p.267). Social connectedness can be seen as the subjective cognizance of being in close relation with the social environment, and seems to be related to how other people are seen to be characterized within oneself. Furthermore, people feeling higher levels of social connectedness in their social environment can easily carry off relations with others and join in various activities, while people feeling lower social connectedness in their social environment may not efficiently satisfy their needs and manage their emotions (Lee \& Robbins 1998). In addition, dis-connectedness is described as a lack of positive reinforcement from interactions with others. Accordingly, loneliness is defined as a basic sense of disconnectedness from people (Sullivan, 1953, as cited in Wood 1984). Thus it seems to be acceptable that students feeling higher levels of social connectedness in their social environment will likely experience lower levels of loneliness.

\section{Classroom Identity}

Literature review demonstrated that sense of belonging is close in meaning to 'self-categorization' and essential for individuals' identification with a group (Bollen \& Hoyle, 1990; Sulava, 2010). People classify themselves and others in their environments into various social groups based on some group-defining characteristics ascribed to or abstracted from the members in order to locate or define themselves in their social world (Meal \& Ashforth, 1992; van Knippenberg \& Sleebos, 2006). When individuals make such a categorization, they are inclined to compare themselves with other people in their social environment on the basis of their membership to a specific group. Since individuals are striving to have a positive self-esteem based partially on their social identity, they want to make certain that this particular group is a source of positive identity while assigning themselves into this group as members (Edward 2005; van Dick, 2001). Specifically, social identity approach has been consisted of social identity and self-categorization theories addresses group identity and the implications for self and relation to others (Ashforth \& Meal, 1989; Meal \& Ashforth, 1992; Spears, 2011). Individuals' social identification with a social group to which they belong is a significant experience connecting them to the group, and expresses them both who they are and who they are not. Consequently, social identity seems to be a product of a social categorization process and of identification with a group individuals belong to, which they then characterize as part of themselves (Meal \& Ashforth, 1992; Spears, 2011; Wortham, 2004). In this respect, sense of belonging is viewed as essential to individuals' identification with a social group and has several consequences for their behaviors (Bollen \& Hoyle, 1990; Sulava, 2010).

Furthermore, identification has been used to denote a form of attachment that is formed between an individual and a person or a social group or an institution, such as class or school (Voelkl, 1997). This perspective claimed that individuals come to identify with a social group or institution representing particular expectations, values, beliefs and practices. Voelkl (1997) proposed that students who identify themselves with their schools and classes may exhibit positive attitudes toward schooling and display suitable personal and social behaviors in the classroom, such as conformity to rules and regulations. However, some particular problems, such as feeling of alienation, hostility, tension, negative school attitudes, disruptive behaviors, school crime and dropping-out can be observed among students when they fail to identify themselves with their classes or schools (Finn, 1989; Scanlon, Rowling, \& Weber, 2007; Voelkl, 1997).

In summary, the conditions or the factors positively related with university students' perceptions of belonging or sense of community has been unexplored in detail, although research has pointed out that students' sense of school belonging is one of the essential factors associated with positive aspects of students' school-related experiences. Accordingly a number of researchers have emphasized on the need for more research focused on university students' sense of belonging to further understand the role this plays in academic contexts (Booker, 2008; Freeman, Anderman \& Jensen, 2007; Pittman \& Richmand, 2008; Tuhanioglu, 2017). As a result of reviewing related literature, it can be stated that each factor aforementioned above has been investigated by associating with school belonging separately or three in one. So in this study, theoretical relationships between students' sense of classroom belonging and four other university class-level variables were associated in a theoretical model. Specifically, considering students' high sense of 
community, as an experience of belonging attained through reciprocally positive and supportive relationships among students and also between students and faculty members has been significantly related with low level of loneliness and also identification with school or class as social group, it has been seen as a mediator among aforementioned four other university class-level variables.

With this background, the present study has been conducted to test a hypothetical model presented in Figure 1 in order to examine the association between students' sense of classroom belonging along with four other university class-level variables including faculty-students relationships, connected classroom climate referring peer relationship, loneliness and classroom identity by using structural equation modeling. Several studies have been carried out to investigate the factors associated with the quality of teacher education, and of their professional development. Most of them placed emphasis on academic, social and psychological conditions or atmosphere in which future teachers are educated, and also the importance of the traditional role of teacher educators on teacher education. The literature showed that educators shape students' learning environment by effective classroom management strategies through creating an atmosphere of acceptance and mutual respect, developing supportive and positive relationships among students, planning lessons considering students' readiness, forming behavioral guidelines, supporting cooperative behaviors and being a role model for respectful and appropriate communicative behaviors and exhibitions of pro-social behavior (Burden 2003; Cangelosi 2004; Jennings \& Greenberg 2009; Jones \& Jones, 1998). Through modeling, teacher educators display certain professional and social behaviors which can be seen as more influential in pre-service teachers' professional and social development than the knowledge provided to them (Wideen et al., 1998). In this respect, preservice teachers attending the faculty of education was selected as sample of this study.

Pre-service teachers' sense of belonging was considered at classroom level in the present study, because all the preservice teachers, at the same grade from the same department of the faculty, who were selected for participation in the present study, take compulsory courses together as a class. There are a few elective courses delivered to the pre-service teachers at each grade, but in general, they take these elective courses as whole class. In sum, pre-service teachers in the same grade from the same department of the faculty are trained in the same class from beginning to end of their four year teacher training programme. So, it is reasoned that these classes can be seen as social groups (Fassinger 1997). Specifically, the present investigation attempted to test a hypothetical model presented in the following figure.

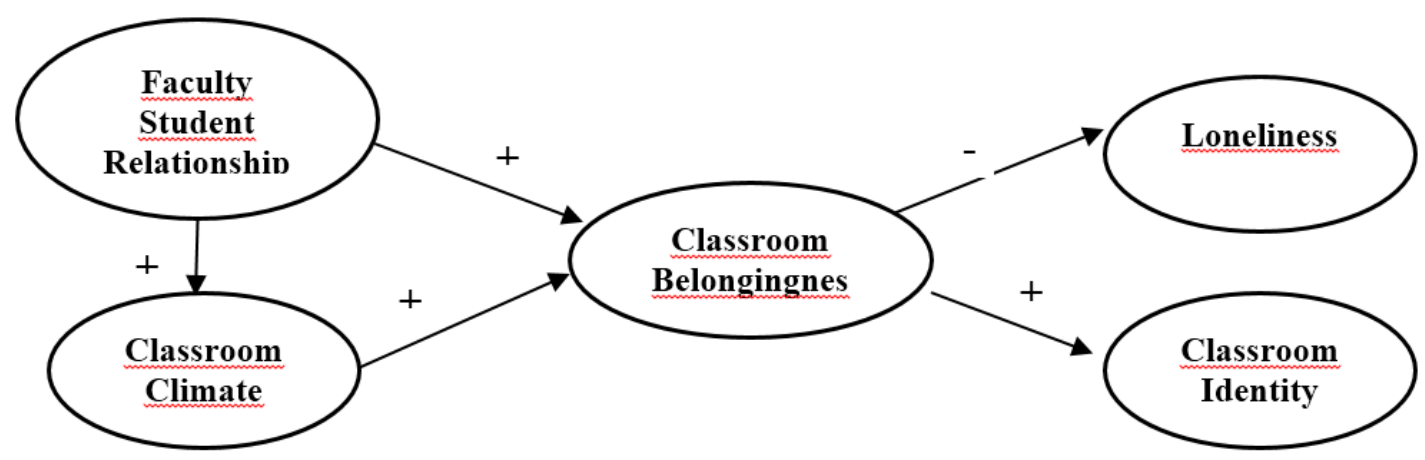

Figure 1. Hypothetical model of the interrelationships among classroom belongingness, classroom identity, faculty-student relationship, classroom climate and loneliness among pre-service teachers.

\section{Methodology}

\section{Research Goal}

The present study aims at testing a hypothetical model in order to examine the association between students' sense of classroom belonging along with four other university class-level variables including faculty-students relationships, connected classroom climate referring peer relationship, loneliness and classroom identity by using structural equation modeling.

\section{Sample and Data Collection}

The Faculty of Education was selected as a case from a university which is one of 103 publicly founded universities in Turkey. When compared to other faculties of education in Turkey, it has a relatively long history and high quality facilities. The sample of this study composed approximately all of the pre-service teachers enrolled in the faculty. Specifically, the sample of this study consisted of 1425 pre-service teachers. Out of 1425 pre-service teachers, 903 were female (63.4\%) and 522 were male (36.6.9\%). The mean age of the sample was 21.09 (SD=1.83), with an age range of 
17 to 28 years. Of these pre-service teachers, $31.2 \%(n=444)$ were freshman, $26.6 \%$ were sophomores $(n=379)$, $21.3 \%$ were juniors $(n=304)$ and $20.9 \%$ were seniors $(n=298)$.

\section{Measures}

Each measures used in this study was adapted for pre-service teachers through confirmatory factor analysis in order to test specific predictions concerning each measure's structure and the results revealed that all measures have adequate psychometric properties. Measurement model statistics of the measures using as latent variables in the hypothesized structural model were shown in the result section of this study.

Sense of belonging was measured by the Sense of Belonging sub-scale of the Perceived Cohesion Scale (PCS), developed by Bollen and Hoyle (1990), with a sample of university students. The measure involves 3 items, with scores ranging from 3 to 15. The higher scores indicate higher sense of belonging to a precise group. The results of confirmatory factor analysis (CFA) done to adapt this sub-scale for pre-service teachers supported the one-factor model of this sub-scale with adequate values of various fits of indices (see Table 1). In addition, the internal consistency of 3 items of this subscale is .95 for this study.

Classroom climate was assessed by using Connected Classroom Climate Inventory (CCCI). The 18-item, onedimensional, Likert-type, CCCI originally was developed by Dwyer et al. (2004) for using university samples. The items in the CCCI reflect behaviors exhibited among students affecting students' perceptions of a supportive classroom climate. The overall reliability for the original scale was $\alpha=0.94$. The researcher adapted the CCCI to Turkish with a validity study (see Table 1). CFA results showed that the 13-item scale, which excluded five items with small parameter estimates including factor loadings $(\lambda<50)$ and squared multiple correlations $\left(\mathrm{R}^{2}<0.30\right)$, was a better fit for the data. The internal consistency coefficient of the adapted scale as estimated by Cronbach's Alpha was 0.92 in this study.

Classroom identity was measured by using four items of Organizational Identification Scale adapted from Mael and Ashforth (1992). An example item is "this class' successes are my successes", which was rated from 1 (strongly disagree) to 5 (strongly agree). These 4 items had an internal consistency of alpha value of 0.78 .

Faculty-student relationship (FSR) was measured by using one of 12 sub-scales of Comprehensive Assessment of School Environment (CASE) developed by University of Nebraska and Western Michigan University for National Association of Secondary School Principals in1982. The CASE was adapted in Turkish for high school students, and validity and reliability of the scale have been supported by Acarbay (2006). The sub-scale of faculty-student relationships was composed of 12 items scored on a 5 -point scale. Based on the Turkish version of the CASE, in order to make this subscale adequate for university students, the word 'teacher' was replaced by the word 'faculty member' and the items were adjusted for this study, e.g. "faculty members are willing to help students", and "faculty members help students to be friendly and kind to each other". The validity study of this sub-scale scores have also been provided by the researcher (see Table 1). The FSR had an internal consistency in this study of Cronbach's Alpha 0.92.

Loneliness was measured by the short-form UCLA Loneliness Scale (ULS-8), containing the 8 items selected from the UCLA Loneliness Scale (Russell, Peplau, \& Ferguson 1978) by Hays and DiMatteo (1987). The items scored on a 4 -point scale ranging from 1 (never) to 4 (always). The Turkish adaptation of the UCLA for university students was done by Demir (1989), and adequate psychometric properties were reported by the same researcher. Support for the construct validity of the short-form scale scores were also provided in the present study (see Table 1). In this study, the internal reliability of the adapted ULS-8 was 0.82 .

\section{Analyzing of Data}

In this study, structural equation modeling testing the theoretical model (Figure 1) was used with the LISREL 8.30 program (Joreskog \& Sorbom 1999). In the analyses, first, a series of confirmatory factor analyses were done to determine the adequacy of the study variables (see Table 1). Then, the hypothesized relationships among study variables based on the theoretical model was tested and direct/indirect effects among variables were examined. The LISREL analyses were performed using covariance matrices and the maximum likelihood estimation method. Moreover, non-significant paths in the hypothesized model were deleted in a subsequent process of "model-trimming" (Byrne, 2001) for improving the model.

\section{Findings}

\section{Confirmatory Factor Analyses}

Confirmatory factor analysis is mainly used to process the relationship between indicator variable and latent variable in order to test the strength of fit of the theoretical model (Hoyle, 1995). For this reason, the measurement model statistics of each study variable using in the hypothesized model was assessed through confirmatory factor analysis. As shown in Table 1, the fit indices for five study variables indicate that they have adequate psychometric properties. 
Table 1. Factor Loadings, Inter-item Correlations, and Fit Indices for Latent Variables

\begin{tabular}{llllllllllll}
\hline $\begin{array}{l}\text { Latent } \\
\text { Variables }\end{array}$ & $\begin{array}{l}\text { Number } \\
\text { of Items }\end{array}$ & $\begin{array}{l}\text { Range of } \\
\text { Factor } \\
\text { Loadings }\end{array}$ & $\begin{array}{l}\text { Range of } \\
\text { Inter-Item } \\
\text { Correlations }\end{array}$ & $\chi^{2}$ & sd & $\chi^{2} / \mathbf{s d}$ & RMSEA & SRMR & GFI & AGFI & CFI \\
\hline Belonging & 3 & $.88-.95$ & $.86-.91$ & 0 & 0 & 0 & 0 & 0 & 1 & 1 & 1 \\
Identity & 4 & $.59-.75$ & $.53-.64$ & 0.1 & 1 & 0.1 & 0 & 0 & 1 & 1 & 1 \\
Climate & 12 & $.55-.85$ & $.53-.78$ & 68.7 & 37 & 1.9 & 0.03 & 0.02 & .99 & .98 & 1 \\
Faculty & 11 & $.62-.77$ & $.60-.76$ & 52.4 & 28 & 1.9 & 0.02 & 0.01 & .99 & .98 & 1 \\
Loneliness & 8 & $.58-.78$ & $.39-.65$ & 5.6 & 7 & 0.8 & 0 & 0.01 & 1 & .99 & 1 \\
\hline
\end{tabular}

\section{Descriptive Statistics}

The descriptive statistics including means, standard deviations, bivariate correlations, and internal consistency reliabilities for the latent variables used in the structural equation model are also shown in Table 2 . Bivariate correlation coefficients indicated moderate to strong positive relationships among latent variables with the exception of loneliness scale, which was either indicating small to moderate negative relationships, or was not significantly correlated remaining latent variables. Overall, the variables did not appear to correlated enough to make multicolinearity a serious concern (e.g., >.70; Tabachnick \& Fidell 1996). Moreover, Cronbach's alpha coefficients reflected mostly high internal consistency reliability among the items on each latent variable.

Table 2. Descriptive Statistics, Bivariate Correlations, and Cronbach's Alpha Coefficients

\begin{tabular}{llllll}
\hline Latent Variables & $\mathbf{1}$ & $\mathbf{2}$ & $\mathbf{3}$ & $\mathbf{4}$ & $\mathbf{5}$ \\
\hline 1. Classroom Identity & - & & & & \\
2. Classroom Belongingness & $.547^{*}$ & - & & & \\
3. Classroom Climate & $.557^{*}$ & $.626^{*}$ & - & & - \\
4. Faculty-Student Relationship & $.279^{*}$ & $.206^{*}$ & $.332^{*}$ & - & \\
5. Loneliness & $-.098^{*}$ & $-.281^{*}$ & $-.174^{*}$ & -.075 & 13.87 \\
\hline Mean & 12.05 & 10.00 & 40.76 & 31.05 & 4.80 \\
Standard Deviation & 3.55 & 3.31 & 9.49 & 8.95 & .82 \\
$\alpha$ & .78 & .95 & .92 & .92 &
\end{tabular}

\section{Structural Equation Modeling}

The hypothesized structural equation model for interrelationships among classroom identity, sense of classroom belonging, classroom climate, faculty-pre-service teacher relationships and loneliness of pre-service teachers was tested to determine its fit with the obtained data. Although the hypothesized model demonstrated a reasonable fit to data $\left(\chi^{2}{ }_{(653)}=1406.03, \chi^{2} / s d=2.15, \mathrm{RMSEA}=0.028, \mathrm{SRMR}=0.049, \mathrm{GFI}=0.95, \mathrm{AGFI}=0.94\right.$ and CFI=0.97), the hypothesized path between faculty and pre-service teacher relationships and sense of classroom belonging was not significant $(\beta=0.02, t=0.66)$. Since dropping this path would not significantly decrease the model fit, this path was deleted. In addition, the modification indices suggested that the addition of a path both between classroom climate and faculty-student relationships, as well as between classroom climate and classroom identity, would significantly improve the model fit and these changes seemed to be acceptable, as the modification was theoretically plausible.

Consequently, the result of the structural equation modeling for the final (modified) model yielded the following goodness-of-fit indices: $\chi^{2}{ }_{(648)}=1178.81, \chi^{2} / s d=1.82$, RMSEA $=0.024$, SRMR $=0.034, \mathrm{GFI}=0.96, \mathrm{AGFI}=0.95$ ve CFI= 0.98. These indices indicated that the final model proved more adequate than the hypothetical model, in order to interpret significant relationships among study variables. Figure 2 illustrates the standardized direct relationships in the final model. All direct relationships were statistically significant at the $p<.05$ level and the standardized path coefficients changed between -0.30 and 0.68 , indicating medium to large effect with respect to Cohen's criteria (as quoted in Schoon, Sacker, \& Bartley 2003). Specifically, examination of paths suggested that the faculty- pre-service teacher relationship was associated with classroom climate, which in turn was associated with sense of classroom belonging and classroom identity. Moreover, a sense of classroom belonging has a positive impact on classroom identity whereas it has a negative direct influence on loneliness. Thus, the final model explained $50 \%$ of the variance in classroom identity, $47 \%$ in a sense of classroom belonging, $14 \%$ in classroom climate, and $9 \%$ in loneliness. 


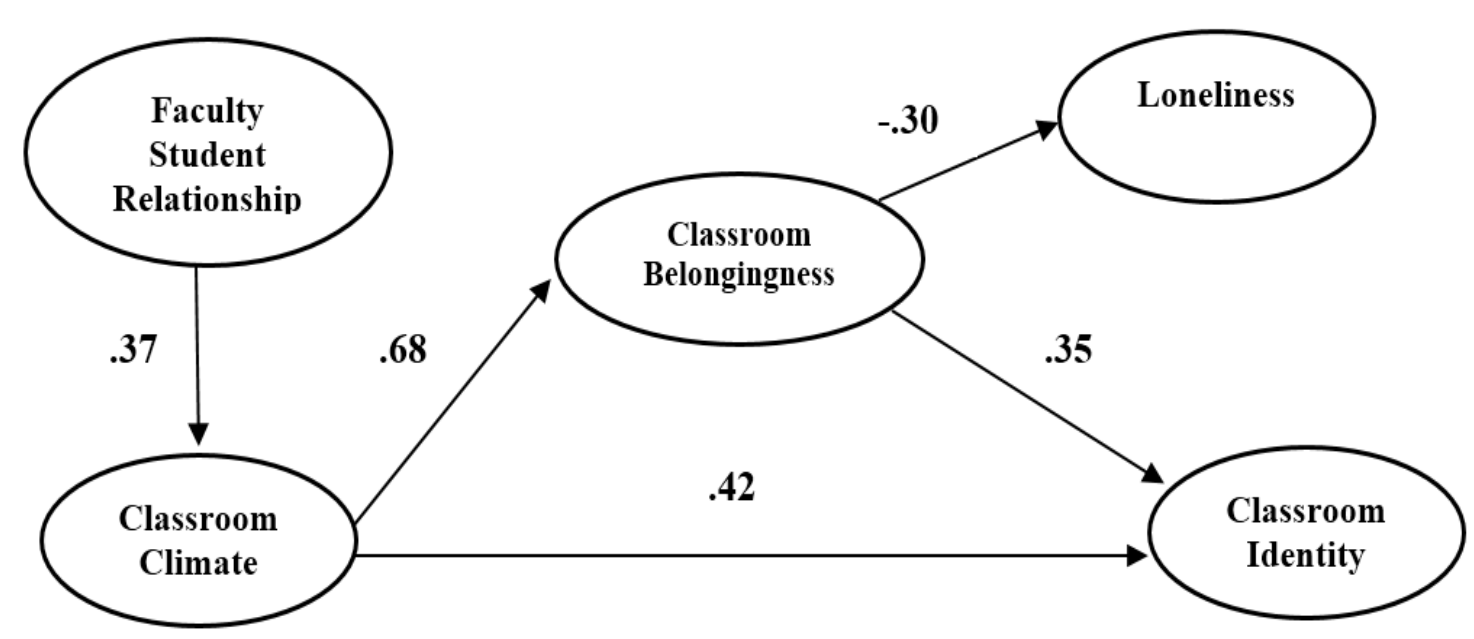

Figure 2. Final Structural Model of the Interrelationships among Faculty-Student Relationship, Classroom Climate, Classroom Belongingness, Loneliness and Classroom Identity

Table 3 indicates the standardized indirect relationships among latent variables used in the final structural model. All indirect (mediated) paths were also statistically significant at the $p<0.05$ level, while the standardized path coefficients changed between -0.21 and 0.25 , indicating slightly moderate indirect effects. The decomposition of the indirect paths showed that the relationship between faculty and pre-service teachers had a positive indirect influence on a sense of classroom belonging and classroom identity through classroom climate, and a negative indirect impact on loneliness, through classroom climate and then a sense of classroom belonging. Finally, classroom climate had a positive indirect relationship with classroom identity, and a negative indirect relationship with loneliness mediated by a sense of classroom belonging.

Table 3. Standardized Indirect Effects

\begin{tabular}{lllr}
\hline Path & & & Effect \\
\hline Classroom Climate & $\longrightarrow$ & Classroom Identity & .24 \\
Classroom Climate & $\longrightarrow$ & Loneliness & -.21 \\
Faculty-Student Relationship & $\longrightarrow$ & Classroom Identity & .24 \\
Faculty-Student Relationship & $\longrightarrow$ & Classroom Belongingness & .25 \\
Faculty-Student Relationship & $\longrightarrow$ & Loneliness & -.21 \\
\hline
\end{tabular}

\section{Discussion and Conclusion}

The results indicated that the final structural model representing the interrelationships among pre-service teachers' sense of classroom belonging, classroom identity, relationships between faculty and pre-service teacher and connected classroom climate, as well as loneliness, to be significant. It was observed that the results of this study are consonant with the literature in showing that students provided with a supportive, connected classroom climate provided by their faculty, experience greater feelings of belonging and tend to identify with their classrooms, whilst also experiencing low level of loneliness.

Specifically, the results revealed that there was a direct relationship between pre-service teachers' sense of classroom belonging and classroom climate, and that the relationship between faculty and pre-service teachers had the strongest indirect impact on a sense of classroom belonging. Similarly, Cox et al. (2009) have acknowledged that there was a positive association between students' perceptions on their teachers' cooperative and supportive behaviors providing students opportunities to build social connections in classroom and their feeling of relatedness. Besides the teacherstudent relationship, these authors view student social connectedness with peers referring supportive, cooperative, respectful and close friendships among students as an important factor leading them to experience a sense of belonging in class.

It is also stated in the literature that teachers shape students' learning environment by effective classroom management strategies, through encouraging cooperation among students, developing supportive and encouraging close relationships among students, establishing and implementing behavioral guidelines, designing lessons building on students' strengths and abilities, and being a role model for respectful and appropriate communication and exhibitions of pro-social behavior (Burden, 2003; Jennings \& Greenberg 2009). Moreover, Cox et al. (2009, p.771) specifically 
suggested that "students may benefit from more opportunities to interact and form relationships with many different students as well as creating an atmosphere of acceptance and mutual respect".

In addition, it was also observed in this study that classroom climate had a direct relationship to the classroom identity. It is stated that a university student's perceptions of peer friendliness and support lead to positive increase in peer interaction within the classroom (Fassinger, 1995; 1997; Sidelinger \& Booth-Butterfield, 2010). Because identification involves seeking self-defining relationships with other individuals to adopt certain attitudes and values (Becker, 1992), interaction among students in the classroom holds importance for their processes of identification. In sum, it can be stated that establishing supportive relationships enhances the perception of classroom identity among students. The results also showed that classroom climate had an indirect impact upon classroom identity through classroom belongingness. Considering the sense of belonging as an essential part of an individual's identification process with a group (Bollen \& Hoyle, 1990; Sulava, 2010), the result of the present study indicating the indirect impact of classroom climate on classroom identity appears plausible. As a result, we propose classroom climate to be a source of classroom belonging and classroom identity, typically facilitated by supportive relationships among pre-service teachers and also between faculty and pre-service teachers.

The results also showed that there was a negative indirect relationship between classroom climate and loneliness mediated by a sense of classroom belonging. Chuiper (2001) has emphasized that lack of sense of community leads individuals to experience loneliness, alienation and to feel social isolation. In other words, lack of belonging might induce to experience loneliness, alienation, to feel social isolation, upon which, in order to avoid feelings of loneliness, individuals it may become necessary for individuals to feel they are part of something, and to be accepted and respected by others, in order that they develop a sense of belonging or connectedness.

Teacher educators influence pre-service teachers' professional development as a role model exhibiting particular behaviors, such that pre-service teachers not only gain knowledge by listening and reading about teaching, but they are also able to experience it. Through modeling, teacher educators themselves are illustrations of the viewpoints, values, attitudes and behaviors they are trying to improve in pre-service teachers. In this way, teacher educators contribute to the socialization of pre-service teachers, shaping their own practices accordingly (Lunenberg et al., 2007). Similarly, Wideen et al. (1998) have proposed that the way teacher educators model the promotion of certain behaviors can be seen as a main factor in affecting teacher behavior than the knowledge that is provided to them, despite the inherent differences between university and school contexts. This study seeks to inform teacher educators on the influence of their own teaching and classroom management behaviors, which can be displayed to develop an atmosphere of communality and belonging on the learning of pre-service teachers.

In addition, Glasser (1999) believed that belonging provides motivation for students to study and theorizes belonging as a prerequisite for achievement. So as to improve the quality of teacher education and future teachers, it can be recommended that teacher educators should focus on the need for each pre-service teacher to experience a sense of belonging in the classroom through effective classroom management strategies, in order to develop an atmosphere of communality and belonging. In other words, it can be concluded that teacher educators should be encouraged to be supportive and positive to pre-service teachers throughout the latter's training, while also creating a positive climate in which pre-service teachers have positive and supportive close relationships in classroom.

In addition, it should be mentioned that pre-service teacher training curriculum and their training environments need to be revised for improving their knowledge and skills on interpersonal relationships in an educational context and students' psychological, social and academic needs by university policy developers. Furthermore, it can be stated that university policy developers should pay attention to the instructional and classroom management skills of faculty members at other faculties as well as teacher educators' instructional and classroom management skills in order to have positive impact on university students' social and academic adjustment, persistence and attrition, sense of belonging, satisfaction with college, and academic achievement.

Also, it must be stated that the results of this study must be considered as an expression of pre-service teachers' perceptions associated with sense of classroom belonging, classroom identity, faculty-students relationships, connected classroom climate referring student-to-student perceptions of a cooperative and supportive communication atmosphere in the classroom, and loneliness at only one point in time and place. In other words, although pre-service teachers in several institution of higher education are possibly to share common perceptions, the readers must be cautious in generalizing the results of the present study. In other words, further research should examine whether the fitted model attained in this study is also valid in other universities. Furthermore, the model should be re-tested overtime.

Hofstede's cultural dimensions theory (Hofstede et al., 2010) has been seen as an influential theory to understand cultural differences in educational studies. For example, Cortina, Arel and Smith-Darden (2017) examined the influence of the cultural dimensions of individualism/collectivism and power distance on the sense of school belongingness among 15-year-old students from 31 countries. The results of their study indicated that lower school belongingness was observed among students living in a culture with high degree of power distance than students living in a culture with more lateral power relationships. Also they concluded that "Positive teacher student relations and preference for 
cooperative learning environment predict higher school belongingness across cultures" (p.1). Thus, they claimed that some aspects of schooling are sensitive to the cultural context, for example teaching practices emphasizing cooperation over competition among students. Because culture in which individuals brought up is influential in ways of thinking and the general sense of connectedness (or not) among individuals, it is recommended that the model should be retested among university students in different cultures.

\section{References}

Acarbay, F. Y. (2006). Kapsamli Okul Iklimini Degerlendirme Olcegi'nin (ogrenci formu) Turkce dilsel esdegerlik guvenirlik ve gecerlik calismasi [Turkish linguistic equivalence reliability and validity study of Comprehensive School Climate Survey] (Unpublished Master's Thesis). Yeditepe University, Istanbul.

Allen, K., Kern, M., Vella-Brodrick, D., Hattie, J., \& Waters, L. (2018). What schools need to know about fostering school belonging: a meta-analysis. Educational Psychological Review, 30, 1-34. Doi: 10.1007/s10648-016-9389-8

Anderman, L. H. (2003). Academic and social perceptions as predictors of change in middle school students' sense of school belonging. The Journal of Experimental Education, 72(1), 5-22. doi: 10.1080/00220970309600877

Ashforth, B. E., \& Mael, F. (1989). Social identity theory and the organization. The Academy of Management Review, 14(1), 20-39.

Becker, T. E. (1992). Foci and bases of commitment: Are they distinctions worth making. Academy of Management Journal, 35, 232-244.

Booker, K.C. (2008). The role of instructors and peers in establishing classroom community. Journal of Instructional Psychology, 35(1), 12-16.

Bollen, K. A., \& Hoyle, R. H. (1990). Perceived cohesion: A conceptual and empirical examination. Social Forces, 69(2), 479-504.

Burden, P. R. (2003). Classroom management: Creating a successful learning community. New York: John Wiley \& Sons.

Byrne, B. N. (2001). Structural equation modeling with Amos: basic concepts, applications, and programming. Mahwah, NJ: Lawrence Erlbaum Associates.

Cangelosi, J. S. (2004). Classroom management strategies: Gaining and maintaining students' cooperation. New York: John Wiley \& Sons.

Chickering, A. W. (1969). Education and identity. San Fransisco, CA: Josey-Bass.

Chickering, A. W., \& Reisser, L. (1993). Education and identity (2nd Ed.). San Francisco: Jossey-Bass.

Chipuer, H. M. (2001). Dyadic attachments and community connectedness: Links with youths' loneliness experiences. Journal of Community Psychology, 29(4), 429-446.

Cortina, K.S., Arel, S. \& Smith-Darden, J.P. (2017). School belonging in different cultures: The effects of individualism and power distance. Frontiers in Educations, 2, 1-11. doi: 10.3389/feduc.2017.00056

Cotton, S. R., \& Wilson, B. (2006). Student-faculty interactions: Dynamics and determinants. Higher Education, 51, 487519.

Cox, A., Duncheon, N., \& McDavid, L. (2009). Peers and teachers as sources of relatedness perceptions, motivation, and affective responses physical education. Research Quarterly for Exercise and Sport, 80, 765-773.

Demir, A. (1989). UCLA Yalnizlik olceginin gecerlik ve guvenirligi [Reliability and validity studies of UCLA Loneliness Scale]. Psikoloji Dergisi, 6(22), 1- 6.

Duru, E. (2008). The predictive analysis of adjustment difficulties from loneliness, social support, and social connectedness. Kuram ve Uygulamada Egitim Bilimleri / Educational Sciences: Theory \& Practice, 8(3), 849-856.

Dwyer, K. K., Bingham, S. G., Carlson, R. E., Prisbell, M., Cruz, A. M., \& Fus, D. A. (2004). Communication and connectedness in the classroom: Development of the connected classroom climate inventory. Communication Research Reports, 21(4), 264-272.

Edwards, M. R. (2005). Organizational identification: A conceptual and operational review. International Journal of Management Reviews, 7(4), 207-230.

Fassinger, P. A. (1995). Professors' and students' perceptions of why students participate in class. Teaching Sociology, $24,25-33$

Fassinger, P. A. (1997). Classes are groups. College Teaching, 45(1), 22-26.

Finn, J. D. (1989). Withdrawing from school. Review of Educational Research, 59(2), 117-142. 
Freeman, T. M. (2005). Sense of belonging in higher education: Relations to instructor practices, motivation, and achievement (Unpublished Doctoral Dissertation. University of Kentucky, Kentucky, USA). Retrieved fromhttp://search.proquest.com/docview/304995173/fulltextPDF/8C959628EFB94D7BPQ/1?accountid=12398

Freeman, M. T., Anderman, H. L., \& Jensen, J. M. (2007). Sense of belonging in college freshmen at the classroom and campus levels. The Journal of Experimental Education, 75(3), 203-220.

Glasser, W. (1999). Okulda kaliteli egitim (Trans. Kaplan, U.). Istanbul: Beyaz Yayinlari.

Halawah, I. (2006). The impact of student-faculty informal interpersonal relationships on intellectual and personal development. College Student Journal, 40(3).

Hirschy, A. E., \& Wilson, M. E. (2002). The sociology of the classroom and its influence on student learning. Peabody Journal of Education, 77(3), 85-100.

Hoffman, E.M. (2014). Faculty and student relationships: Context matters. College Teaching, 62(1), 13-19.

Hofstede, G., Hofstede, G. J., \& Minkov, M. (2010). Cultures and Organizations: Software of the Mind. New York: McGrawHill.

Hoyle, R. H. (1995). Structural equation modeling: Concepts, issues, and applications. Thousand Oaks, CA: Sage.

Jennings, P. A., \& Greenberg, M. T. (2009). The prosocial classroom: Teacher social and emotional competence in relation to students and classroom outcomes. Review of Educational Research, 79(1), 491-525.

Johnson, L. S. (2009). School contexts and student belonging: A mixed methods study of an innovative high school. The School Community Journal, 19(1), 99-118.

Jones, V. F., \& Jones, L. S. (1998). Comprehensive classroom management: Creating communities of support and solving problems. Boston: Allyn and Bacon.

Joreskog, K., \& Sorbom, D. (1999). LISREL 8.30. Chicago: Scientific Software International Inc.

Juvonen, J. (2009). Reforming middle schools: Focus on continuity, social connectedness, and engagement. Educational Psychologist, 42(4), 197-208.

Lam, U. F., Chen, W. W., Zhang, J., \& Liang, T. (2015). It feels good to learn where I belong: School belonging, academic emotions, and academic achievement in adolescents. Social Psychology International, 36(4), 393-409.

Lamport, M. A. (1993). Student-faculty informal interaction and the effects on college student outcomes: A review of the literature. Adolescence, 28(112), 971-990.

Lee, R. M., \& Robbins, S. B. (1998). The relationship between social connectedness and anxiety, self- esteem, and social identity. Journal of Counseling Psychology, 45(3), 338-345.

Lunenberg, M., F. Korthagen., \& A. Swennen. (2007). The teacher educator as a role model. Teaching and Teacher Education, 23(5), 586-600.

Mael, F. A., \& Ashforth, B. E. (1992). Alumni and their alma mater: A partial test of the reformulated model of organizational identification. Journal of Organizational Behavior, 13(2), 103-123.

Meyers, S.A. (2009). Do your students care whether you care about them? College Teaching, 57(4), 205-210.

Newman, B. M., Lohman, B. J., \& Newman, P. R. (2007). Peer group membership and a sense of belonging: Their relationship to adolescent behavior problems. Adolescence, 42(166), 241-263.

Osterman, K. F. (2000). Students' need for belonging in the school community. Review of Educational Research, 70(3), 323-367.

Pascarella, E., \& Terenzini, P. (1980). Student-faculty and student-peer relationships as mediators of the structural effects of undergraduate residence arrangement. Journal of Educational Research, 73(6), 344-353.

Pittman, L. D., \& Richmond, A. (2008). University belonging, friendship quality, and psychological adjustment during the transition to college. The Journal of Experimental Education, 76(4), 343-361.

Russell, D., Peplau, L. A., \& Ferguson, M. (1978). Developing a measure of loneliness. Journal of Personality Assessment, 42, 290-294.

Ryan, A. M. (2001). The peer group as a context for the development of young adolescents' motivation and achievement. Child Development, 72, 1135-1150.

Scanlon, L., Rowling, L., \& Weber, Z. (2007). You don't have like an identity... you are just lost in a crowd: Forming a student identity in the first-year transition to university. Journal of Youth Studies, 10(2), 223-241. 
Schumacker, R. E., \& Lomax, R. G. (1996). A beginner's guide to structural equation modeling. Mahwah, New Jersey: Lawrence Erlbaum Associates, Pub.

Schoon, I., Sacker, A., \& Bartley, M. (2003). Socio-economic adversity and psychosocial adjustment: A developmentalcontextual perspective. Social Science and Medicine, 57, 1001-1015.

Sidelinger, R. J., \& Booth-Butterfield, M. B. (2010). Co-constructing student involvement: An examination of teacher confirmation and student-to-student connectedness in the college classroom. Communication Education, 59(2), 165-184.

Sulava, K. (2010). At the crossroads of identity, belonging and the myth of return: A case study of Georgian internally displaced persons of 1992-93. (Unpublished Research Paper). Masters of Arts in Development Studies, International Institute of Social Studies, Graduate School of Development Studies, The Netherlands. Retrieved from https://thesis.eur.nl/pub/8657/

Spears, R. (2011). Group identities: The social identity perspective. In Schwartz, S. J., Luyckx, K. \& Vignoles, V. L. (Eds.) Handbook of Identity Theory and Research (pp. 201-224). London: Springer.

Stoeckli, G. (2010). The role of individual and social factors in classroom loneliness. The Journal of Educational Research, 103(1), 28-39.

Tabachnick, B. G., \& Fidell, L. S. (1996). Using multivariate statistics. Northridge: Harper Collins College Pub.

Tinto, V. (1997). Classroom as communities: Exploring the educational character of student persistence. Journal of Higher Education, 68(6), 599-623.

Tuhanioglu-Sevinc, S. (2016). Universite birinci sinif ogrencilerinin universite yasamina uyumlarina katki saglayan bireysel ve cevresel faktorlerin incelenmesi [An investigation of individual and environmental factors contributing to the adjustment levels of freshman university students] (Unpublished Doctoral Dissertation). Mersin University, Mersin, Turkey.

Uslu, F., \& Gizir, S. (2017). School belonging of adolescents: The role of teacher-student relationships, peer relationships and family involvement. Educational Sciences: Theory \& Practice, 17, 63-82. doi: 10.12738/ estp.2017.1.0104

Uslu-Gulsen, F. (2017). Yuksekogretimde okul terkinin degerlendirilmesi [Dropout of in higher education] (Unpuslished Doctorate Dissertation). Eskisehir Osmangazi University, Eskisehir, Turkey.

van Dick, R. (2001). Identification in organizational contexts: Linking theory and research from social and organization psychology. International Journal of Management Reviews, 3(4), 265-283.

van Knippenberg, D., \& Sleebos, E. (2006). Organizational identifications versus organizational commitment: Selfdefinition, social exchange, and job attitudes. Journal of Organizational Behavior, 27(5), 571-584.

Voelkl, K. E. (1997). Identification with school. American Journal of Education, 105(3), 294-317.

Wideen, M.F., Mayer-Smith, J., \& Moon, B. (1998). A critical analysis of the research on learning to teach: Making the case for an ecological perspective on inquiry. Review of Educational Research, 68(2), 130-178.

Wood, J. K. (1984). The psychological aspects of loneliness experienced by college students (Unpublished Doctoral Dissertation. Western Michigan University, Michigan, USA). Retrieved from http://search.proquest.com/docview/303310154/fulltextPDF/42647AC7C7F14F97PQ/4?accountid=12398

Wortham, S. (2004). From good student to outcast: The emergence of a classroom identity. Ethos, 32(2), 164-187. 